University of Nebraska - Lincoln

DigitalCommons@University of Nebraska - Lincoln

$6-10-2010$

\title{
Effects of light and temperature on germination of Pyxidanthera brevifolia Wells (Diapensiaceae)
}

Wade A. Wall

Jacob L. Hilton

Thomas R. Wentworth

Janet B. Gray

Matthew G. Hohmann

See next page for additional authors

Follow this and additional works at: https://digitalcommons.unl.edu/usarmyceomaha

This Article is brought to you for free and open access by the U.S. Department of Defense at

DigitalCommons@University of Nebraska - Lincoln. It has been accepted for inclusion in US Army Corps of Engineers by an authorized administrator of DigitalCommons@University of Nebraska - Lincoln. 
Authors

Wade A. Wall, Jacob L. Hilton, Thomas R. Wentworth, Janet B. Gray, Matthew G. Hohmann, and William A. Hoffmann 


\title{
Effects of light and temperature on germination of Pyxidanthera brevifolia Wells (Diapensiaceae) ${ }^{1}$
}

\author{
Wade A. Wall ${ }^{2}$ \\ Department of Plant Biology, North Carolina State University, Box 7612, Raleigh, NC 27695 \\ Jacob L. Hilton \\ Coastal Sciences Department, University of Southern Mississippi, Hattiesburg, MS 39406
}

Thomas R. Wentworth

Department of Plant Biology, North Carolina State University, Box 7612, Raleigh, NC 27695

Janet B. Gray

Endangered Species Branch, Fort Bragg, NC 28310

Matthew G. Hohmann

US Army Corps of Engineers, Engineer Research and Development Center, Box 9005, Champaign, IL 61826

William A. Hoffmann ${ }^{3}$

Department of Plant Biology, North Carolina State University, Box 7612, Raleigh, NC 27695

Wall, W. A. (Department of Plant Biology, North Carolina State University, Box 7612, Raleigh, NC 27695), J. L. Hilton (Coastal Sciences Department, University of Southern Mississippi, Hattiesburg, MS 39406), T. R. Wentworth (Department of Plant Biology, North Carolina State University, Box 7612, Raleigh, NC 27695), J. B. Gray (Endangered Species Branch, Fort Bragg, NC 28310), M. G. HoHMANN (US Army Corps of Engineers, Engineer Research and Development Center, Box 9005, Champaign, IL 61826), and W. A. Hoffmann (Department of Plant Biology, North Carolina State University, Box 7612, Raleigh, NC 27695). Effects of light and temperature on germination of Pyxidanthera brevifolia B.W. Wells (Diapensiaceae). J. Torrey Bot. Soc. 137: 348-354. 2010.-Pyxidanthera brevifolia is an evergreen semiwoody cushion plant endemic to the Sandhills of North and South Carolina, with the majority of populations occurring on Fort Bragg Military Reservation in North Carolina. Currently the species is listed as Endangered in North Carolina and is designated as a Species at Risk (SAR) by the US Department of Defense. Previous studies have suggested that seeds may not be viable because they failed to germinate under controlled conditions. Our objectives in this study were to attempt germination of Pyxidanthera brevifolia seeds, determine the best temperature conditions for germination, and understand more about germination requirements to aid in future restoration efforts. Using seeds that had been stored at room temperature for six months, we performed a germination experiment at the NCSU Phytotron with six treatments, all combinations of three temperature regimes (low $\left(18{ }^{\circ} \mathrm{C}\right.$ day $/ 14{ }^{\circ} \mathrm{C}$ night), medium $\left(22 / 18{ }^{\circ} \mathrm{C}\right)$, and high $(26 /$ $\left.22^{\circ} \mathrm{C}\right)$ ) and two light conditions (light and dark). We monitored the experiment for 13 weeks, recording the number of seeds germinating per dish and the number of days to germination for seeds in each treatment. We found that Pxyidanthera brevifolia produces germinable seeds and that there are significant effects of light and temperature on germination. Highest germination occurred under low temperature and high light conditions (78\%); the combination of high temperature and no light produced the lowest germination (6\%). Seeds exposed to light germinated significantly earlier at the coolest temperature, compared to medium and high temperatures. These results indicate that it is possible to germinate seeds of this rare plant and suggest that germination of Pyxidanthera brevifolia likely occurs in late fall and is dependent on adequate light availability.

Key words: after-ripening, conservation, Diapensiaceae, Fort Bragg Military Reservation, germination, Pyxidanthera brevifolia, Sandhills.

1 Funding was provided by Department of Defense, US Army Engineer Research and Development Center, Construction Engineering Research Laboratory under Agreement \# W9132T-07-2-0019.

2 Author for correspondence. E-mail: wade.wall@ gmail.com

3 The authors thank Fort Bragg Military Reservation, Endangered Species Branch, NCSU Phytotron, Consuelo Arellano, Matthew Cleary, Sherrie Emerine, Kristen Kostelnik, Bruce Sorrie, Andrew Walker, and Alan Weakley.
Developing effective conservation strategies for rare plant species demands a comprehensive understanding of the numerous biotic and abiotic factors that can limit population growth. Efforts to conserve rare plants can benefit from ex situ, or off-site, propagation

Received for publication March 24, 2010, and in revised form June 10, 2010. 
(Schemske et al. 1994, Guerrant et al. 2004), which can be used to provide a source of plants for population augmentation (Brumback et al. 2004, Mooney and McGraw 2007), reintroduction (Bowles and McBride 1996), or for studying questions relevant to species conservation. Ex situ propagation of rare plants has aided studies of physiological tolerance (Wang et al. 2006, Kimball and Campbell 2008, Marchin et al. 2009), phenotypic plasticity (Picotte et al. 2007), pollination (Hackney and McGraw 2001), mating system evolution (Moeller and Geber 2005), and conservation genetics (Levin et al. 1979). Population augmentation and reintroduction can ameliorate negative consequences of commercial over-harvesting of wild populations (Kharkwal et al. 2008) and introduction of exotic pathogens and pests (Lee et al. 1995, Hebard 2001). Information gleaned from studies of ex situ propagation can also provide insights about the response of a species to management (Schwartz and Hermann 1999, Rhoades et al. 2009) and global climate change (Maschinski et al. 2006). Often little is known about the propagation of rare plants because of a lack of study or underreporting of failed attempts. In the case of Pyxidanthera brevifolia B.W. Wells (Sandhills pixiemoss) there is a long history of failed propagation attempts and observations of the species' apparent lack of recruitment from sexual reproduction (Wells 1929, Reynolds 1966, Primack and Wyatt 1975).

Pyxidanthera brevifolia is a winter-flowering evergreen cushion plant (Fig. 1) that occurs in a narrow geographic range within the Sandhills region of North and South Carolina (Wells 1929, Weakley 2008). Currently, $P$. brevifolia is found in six North Carolina counties and two South Carolina counties, with approximately $90 \%$ of the known populations occurring on Fort Bragg Military Reservation, NC (Buchanan and Finnegan 2008). The species is listed by the state of North Carolina as Endangered, designated by the US Department of Defense as a Species At Risk, and ranked by NatureServe as $\mathrm{S} 2$ (imperiled) and S3 (vulnerable) in South Carolina and North Carolina, respectively. Pyxidanthera brevifolia occupies Xeric Sandhill Scrub (Schafale and Weakley 1990), a habitat characterized by an exposed topographic position and excessively well-drained soils that create harsh growing conditions, especially during the summer season (Wells and Shunk 1931). The more wide-ranging congeneric Pyxidanthera barbulata Michx. is found in the outer Atlantic Coastal Plain from northeastern South Carolina to southeastern Virginia, with disjunct populations in the Pine Barrens of New Jersey and older dunes on Long Island, New York. The two species cooccur on Fort Bragg, but are separated ecologically, with $P$. brevifolia occurring in the xeric uplands and $P$. barbulata occurring in ecotones between streamhead pocosins and adjacent pine-dominated woodlands (Schafale and Weakley 1990, Sorrie et al. 2006).

Successful seed germination in the field has not been observed for Pyxidanthera brevifolia, and there has been some question about seed production and viability. Wells and Shunk (1931) observed low seed-set, and the seeds produced appeared to be inviable. Moreover, they observed no seedlings in the field and speculated that $P$. brevifolia populations were clonal relicts maintained by vegetative propagation, though there is scant evidence for this. A subsequent study also observed low seed-set for the species and production of seeds of questionable viability (Reynolds 1966). More recently, Primack and Wyatt (1975) did not find low seed-set; percentages of seed-producing capsules collected from six populations ranged from $22-83 \%$. Nevertheless, all studies conducted thus far have reported a failure to germinate $P$. brevifolia seeds in situ (Wells and Shunk 1931, Reynolds 1966, Primack and Wyatt 1975). Attempts at transplanting $P$. brevifolia have also largely failed (Primack and Wyatt 1975) or have not yet documented survival beyond four years (Hohmann et al. unpublished data).

Successful propagation of Pyxidanthera brevifolia is important because of its limited range, relatively low population numbers, and the pressures that it faces both currently and in the near future. Because of base realignments, Fort Bragg Military Reservation has recently experienced unprecedented expansion, with more than 32,000 new troops being assigned to United States Army Forces Command (FORSCOM). In addition, the nearby city of Fayetteville has also been expanding, and several road projects have led to the destruction of $P$. brevifolia populations. Our objectives in this study were to germinate $P$. brevifolia seeds to aid in possible future population augmentation, restoration, or es- 


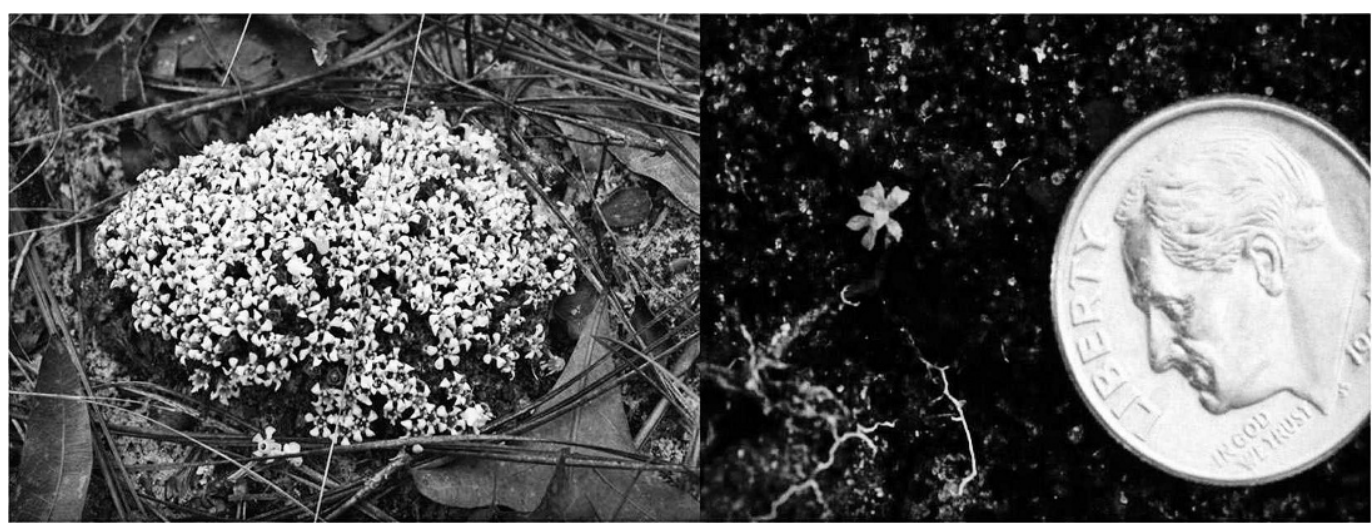

FIg. 1. Winter-flowering Pyxidanthera brevifolia in full bloom on Fort Bragg (left) and ex situ propagated $P$. brevifolia seedling (right). Left photo taken 25 March 2009.

tablishment efforts, to identify the optimal germination conditions for $P$. brevifolia seeds, and to identify possible environmental controls on seed germination for this endemic Sandhills species.

Methods. Seeds were collected during the last two weeks of April 2008 from at least 5 individuals in each of 24 randomly selected Pyxidanthera brevifolia subpopulations representing 19 populations (as delineated by the North Carolina Natural Heritage Program) on Fort Bragg, NC. Seeds were stored in paper envelopes under ambient laboratory conditions at North Carolina State University until November 2008. Seeds from the 24 subpopulations were thoroughly mixed and placed on moistened filter paper in $8.5 \mathrm{~cm}$ diameter Petri dishes. Each dish was randomly assigned to one of six treatments of a factorial experiment consisting of three temperature settings (low, $18{ }^{\circ} \mathrm{C}$ day $/ 14{ }^{\circ} \mathrm{C}$ night; medium, $22 / 18^{\circ} \mathrm{C}$; and high, $26 / 22{ }^{\circ} \mathrm{C}$ ) and two light settings (complete darkness and $12 \mathrm{hr}$ daily exposure to fluorescent light). The temperature settings selected represented available growth chambers. We included five replicate Petri dishes per treatment with 10 seeds per replicate. To simulate complete darkness, Petri dishes in the dark treatment were placed in breathable fabric bags custom designed for the North Carolina State University Phytotron to be both breathable and eliminate all light; seeds in the dark treatment were only light-exposed when monitoring for germination and watering. We monitored the experiment for 13 weeks, recording germination success and time to germination for each seed in the experiment on average every 4.3 days. The experiment was conducted at the North Carolina State University Phytotron.

We tested for main effects of light and temperature on seed germination percentages using a generalized linear model with a binomial error structure and a logit link function as implemented in the statistical program R ( R Development Core Team 2002). We tested for significant effects of light and temperature on the seed germination percentage with a Bonferroni correction using the glht() function from the $\mathrm{R}$ package multcomp (Hothorn et al. 2008). We tested for differences in average time to germination using a linear mixed effects model in the $\mathrm{R}$ package NLME (Pinheiro et al. 2007).

Results. Percentage of germinating seeds across all treatments was $47 \%$, but it varied considerably among treatments. Overall, germination percentage in the light was twice that in darkness $\left(60 \%\right.$ vs $30 \%, X_{1}^{2} d f=20.56, P<$ 0.001 , Fig. 2). Germination percentage was also significantly affected by temperature $\left(X_{2 d f}^{2}=45.8, P<0.001\right)$, but this effect depended on light conditions (temperature $X$ light interaction, $X_{2}^{2} d f=9.03, P=0.011$ ), such that temperature had a much greater effect on the percentage of germinating seeds in darkness than in light. Under the dark condition, germination percentage was higher at low temperature $(52 \%)$ than at medium (30\%, $P<0.001)$ or high $(6 \%, P<0.001)$ temperatures; there were also significant differences in germination percentage under dark 


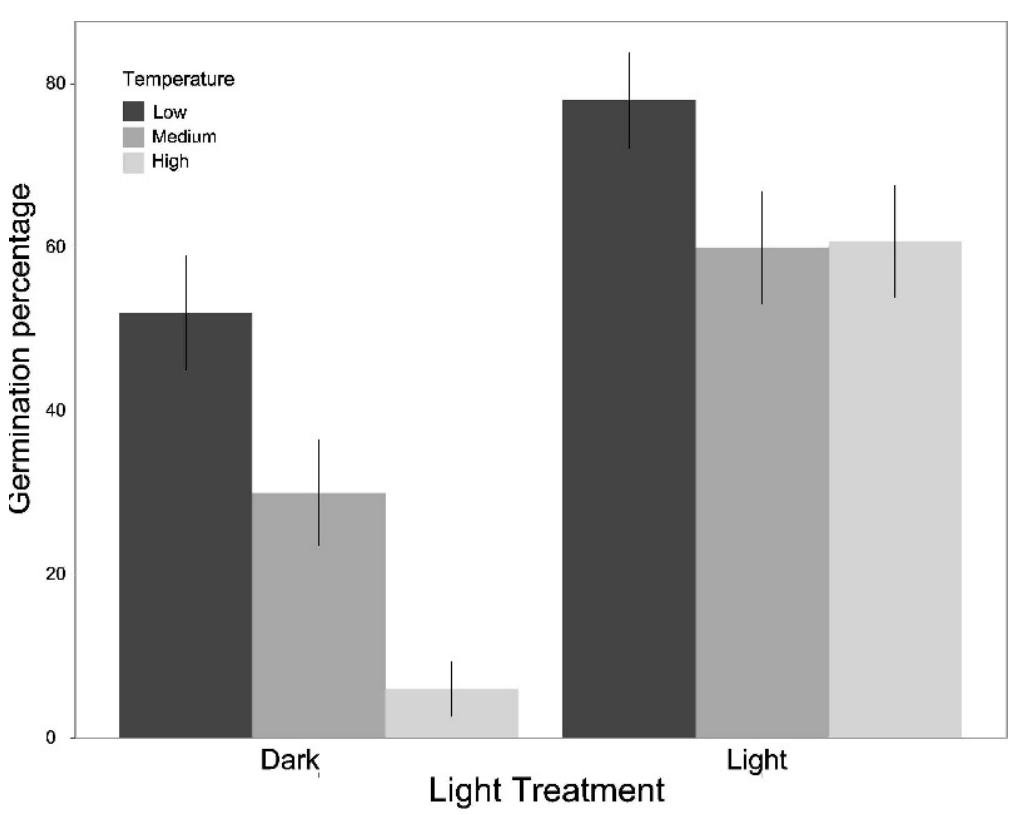

FIG. 2. Effects of light and temperature on percentage of Pyxidanthera brevifolia seeds germinating. Error bars represent \pm 1 standard error, with 5 replicates (10 seeds per replicate) for each treatment. There were significant effects of both light and temperature on the percentage of germinating seeds, but also an interaction between light and temperature.

conditions between the medium and high temperatures $(P<0.001)$. Similar effects were found under light conditions. Germination percentage was significantly higher at low temperature $(78 \%)$ than at medium $(60 \%, P$ $<0.001)$ and high $(61 \%, P<0.001)$ temperatures.

Average time to germination was 55.8 days ( $\pm 18.3 \mathrm{sd})$, but, as with germination percentage, this varied among treatments $\left(F_{2} \mathrm{df}=\right.$ $6.55, P<0.001)$. We only compared time to germination for seeds exposed to light because of low germination percentage under dark conditions at high temperatures. Under low temperature, seeds germinated after an average of 47.3 days $( \pm 2.73 \mathrm{SE}$ ), which was significantly different from average time to germination under medium (58.5 days ( \pm 3.45 SE), $P<0.001)$ and high (63.8 days $( \pm 2.80$ $\mathrm{SE}), P<0.001)$ temperatures. Average time to germination did not differ between medium and high temperatures.

Discussion. Our study dispels speculation that Pyxidanthera brevifolia has a low capacity to produce viable seeds. Our observations (unpublished) also support the finding of Primack and Wyatt (1975) that P. brevifolia does not suffer from low seed-set, with Fort Bragg populations producing a mean of 10 seeds per capsule. In contrast to previous studies, we found that $P$. brevifolia does produce viable seeds, with germination rates as high as $78 \%$ when 6 month old seeds were exposed to light and low $\left(18 / 14{ }^{\circ} \mathrm{C}\right)$ temperature. It is not clear why previous attempts to germinate this species were unsuccessful, but the relatively long time to germination (79 weeks) may have been a factor if trials were not continued for sufficient lengths of time.

Previous attempts to propagate Pyxidanthera brevifolia from seed can be separated into studies conducted in situ and those conducted ex situ. The reason why in situ efforts have largely failed is difficult to evaluate, but we can explore why ex situ experiments have failed. Although our study was not specifically designed to investigate dormancy and represents a snapshot of a continually varying process, the available information points to the importance of after-ripening of $P$. brevifolia seeds for breaking dormancy. Unfortunately, there is great variability in the methodological details for previous attempts to germinate $P$. brevifolia seeds. Primack and Wyatt (1975) reported a 
failure to germinate seeds, but provided no detail on whether seeds were fresh or afterripened. Two subsequent studies used freshly harvested seeds from $P$. brevifolia populations on Fort Bragg; both studies failed to document any germination (Shapiro et al. 2000) (Hohmann et al. 2002). Although gibberellic acid is known to promote germination in seeds exhibiting physiological dormancy and ordinarily requiring light (Kahn et al. 1957, FinchSavage and Leubner-Metzger 2006), application of gibberellic acid at varying concentrations failed to induce germination in $P$. brevifolia seeds (Hohmann, unpublished data). It is also possible that this last study was not of sufficient duration to observe germination, given that our results showed delayed germination at higher temperatures. However, Shapiro et al. (2000) reported germination of $P$. brevifolia seeds from the seed bank after soil was collected near $(<1 \mathrm{~m})$ adult plants in July, moistened and placed under growth lights for 12 weeks.

The slow germination of this species should substantially limit establishment success during the warmer months in its typical habitat. From late spring to early fall, xeric soils of the Sandhills region are unlikely to remain continuously moist for the time necessary for germination and successful establishment (Wells and Shunk 1931, Doublin and Grundstein 2008). This is particularly true for surface soils where germination must occur if the seedling is to survive. Owing to the small seeds $(0.6-0.8 \mathrm{~mm})$ of this species (Radford et al. 1968), if germination were to occur in deeper soils that are buffered from rapid drying, the cotyledons would be unable to reach the surface, and seedlings would suffer high mortality rates. Previous studies have also demonstrated that small-seeded species in general require light for germination (Grime et al. 1981). Although there was a significant effect of light on the percentage of germinating seeds (Fig. 2), Pyxidanthera brevifolia is capable of some germination in the dark. This result may be due to the exposure of darktreatment seeds to light during monitoring episodes. It was not possible to exclude all light, and although we attempted to minimize light exposure, all dark-treatment seeds were light-exposed to some extent.

The conditions that favor germination of Pyxidanthera brevifolia in the NC Sandhills are most prevalent in the late fall and early winter, when temperatures are cooler and rainfall is only slightly less than in the summer months. Although the temperature range of the present study did not include a temperature low enough to capture decreased germination percentages due to colder temperatures, it is clear that germination percentages decrease above $18{ }^{\circ} \mathrm{C}$ (Fig. 2). Pyxidanthera brevifolia appears to have adapted to the environmental constraints of the Sandhills climate by having germination cued to cool temperatures and high light conditions. This relatively low temperature optimum, and the fact that $P$. brevifolia does not appear to need cold stratification, points to a fall or early winter germination. Cues for fall germination would be advantageous and allow for a longer growing period before seedlings experience extreme summer conditions, which are characterized by frequent soil moisture deficits (Doublin and Grundstein 2008). Pyxidanthera brevifolia is a slow-growing species with small seeds, and spring germination would most likely not allow enough time for root establishment before onset of the higher temperatures and drought conditions that occur during the summer months in the Sandhills region. Although our data support fall germination, laboratory conditions do not replicate natural settings; field trials will be necessary to test this hypothesis rigorously.

Our phytotron data suggest that germination of Pyxidanthera brevifolia occurs in the cooler months of fall and winter. If this proves the case in natural populations, we can find interesting parallels in other habitats. Seedling germination at relatively low temperatures has been observed in Mediterranean environments as well (Thanos et al. 1989) and has been termed the "Mediterranean" germination syndrome (Fenner and Thompson 2005), although these effects are not limited to the Mediterranean region (Grime et al. 1981). In this syndrome, increasing temperature positively affects germination percentage to a certain threshold, at which point the percentage of germinating seeds decreases (Schütz 1997). In Mediterranean areas, summer drought is more likely to cause seedling mortality than cold, and so many species are cued to germinate in the fall or winter.

In conclusion, our results indicate that Pyxidanthera brevifolia produces viable seeds, suggesting that it is possible to propagate this species for restoration purposes. This is an 
important finding, because attempts at relocation have largely failed. Our discovery of positive germination response to low temperatures suggests that germination in nature likely occurs in late fall and that germination appears to depend on adequate light to break dormancy. Germination under cooler temperatures may be an adaptation necessary for seedling survival, ensuring that early growth occurs under less stressful conditions. Although further investigation will be necessary to confirm this hypothesis, the germination protocol we produced will be beneficial to future research and conservation efforts focused on Pyxidanthera brevifolia.

\section{Literature Cited}

Bowles, M. L. And J. McBride. 1996. Pitcher's thistle (Cirsium pitcheri) reintroduction, pp. 423-432. In D. A. Falk, C. I. Millar, and M. Olwell [eds.], Restoring diversity: strategies for reintroduction of endangered plants. Island Press, Washington D.C.

Brumback, W. E., D. M. Weihrauch, and K. D. Kimball. 2004. Propagation and transplanting of an endangered alpine species: Robbins' cinquefoil, Potentilla robbinsiana (Rosaceae). Native Plants J. 5: 91-97.

Buchanan, M. And J. T. Finnegan. 2008. Natural Heritage Program List of Rare Plant Species of North Carolina. North Carolina Natural Heritage Program, Raleigh, NC. 140 p.

Doublin, J. K. And A. J. Grundstein. 2008. Warmseason soil-moisture deficits in the southern United States. Phys. Geogr. 29: 3-18.

Fenner, M. And K. Thompson. 2005. The ecology of seeds. Cambridge University Press, New York, NY. 250 p.

Finch-Savage, W. E. and G. Leubner-Metzger. 2006. Seed dormancy and the control of germination. New Phytol. 171: 501-523.

Grime, J. P., G. Mason, A. V. Curtis, J. Rodman, S. R. Band, M. A. G. Mowforth, A. M. Neal, AND S. SHAw. 1981. A comparative study of germination characteristics in a local flora. J. Ecol. 69: 1017-1059.

Guerrant, E., K. Havens, and M. Maunder [eds.]. Ex situ plant conservation: supporting species survival in the wild. Island Press, Washington, DC. 504 p.

Hackney, E. E. And J. B. McGraw. 2001. Experimental demonstration of an Allee effect in American ginseng. Conserv. Biol. 15: 129-136.

Hebard, F. V. 2001. Backcross breeding program produces blight-resistant American chestnuts (Virginia). Ecol. Restor. 19: 252-254.

Hohmann, M. G., M. Bates, and J. Gray. 2002. Germination and seedling survival of Sandhills Pyxie Moss (Pyxidanthera barbulata var. brevifolia). Final Report, United State Army Environmental Research and Development Center, Champaign, IL.
Hothorn, T., F. Bretz, and P. Westfall. 2008. Simultaneous inference in general parametric models. Biom. J. 50: 346-363.

Kahn, A., J. A. Goss, And D. E. Smith. 1957. Effect of gibberellin on germination of lettuce seed. Science 125: 645-646.

Kharkwal, A. C., R. Kushwaha, O. Prakash, R. K. Ogra, A. Bhattacharya, P. K. Nagar, And P. S. Ahuja. 2008. An efficient method of propagation of Podophyllum hexandrum: an endangered medicinal plant of the Western Himalayas under ex situ conditions. J. Nat. Med. 62: 211-216.

Kimball, S. And D. Campbell. 2008. Physiological differences among two Penstemon species and their hybrids in field and common garden environments. New Phytol. 181: 478-488.

Lee, J. C., X. Yang, M. Schwartz, G. Strobel, and J. Clardy. 1995. The relationship between an endangered North American tree and an endophytic fungus. Chem. Biol. 2: 721-727.

Levin, D. A., K. Ritter, and N. C. Ellstrand. 1979. Protein polymorphism in the narrow endemic Oenothera organensis. Evolution 33: 534-542.

Marchin, R. M., R. K. Bhandari, W. A. Wall, M. G. Hohmann, J. B. Gray, and W. A. Hoffmann. 2009. Are rare species less shade tolerant than common species in fire-prone environments? A test with seven Amorpha (Fabaceae) species. Plant Ecol. 205: 249-260.

Maschinski, J., J. E. Baggs, P. F. QuintanaAscencio, And E. S. Menges. 2006. Using population viability analysis to predict the effects of climate change on the extinction risk of an endangered limestone endemic shrub, Arizona cliffrose. Conserv. Biol. 20: 218-228.

Moeller, D. A. And M. A. Geber. 2005. Ecological context of the evolution of self-pollination in Clarkia xantiana: population size, plant communities, and reproductive assurance. Evolution 59: 786-799.

Mooney, E. H. And J. B. McGraw. 2007. Effects of self-pollination and outcrossing with cultivated plants in small natural populations of American ginseng, Panax quinquefolius (Araliaceae). Am. J. Bot. 94: 1677-1687.

Picotte, J. J., D. M. Rosenthal, J. M. Rhode, And M. B. Cruzan. 2007. Plastic responses to temporal variation in moisture availability: consequences for water use efficiency and plant performance. Oecologia 153: 821-832.

Pinheiro, J., D. Bates, S. DebRoy, D. Sarkar, and THE R CORE TEAM. 2009. nlme: linear and nonlinear mixed effects models. $\mathrm{R}$ package version 3.1-93.

Primack, R. B. And R. Wyatt. 1975. Variation and taxonomy of Pyxidanthera (Diapensiaceae). Brittonia 27: 115-118.

R Development Core team. 2002. R: a language and environment for statistical computing. R Foundation for Statistical Computing, Vienna, Austria.

Radford, A. E., H. E. Ahles, and C. R. Bell. 1968. Manual of the vascular flora of the Carolinas. University of North Carolina Press, Chapel Hill, NC. 1183 p. 
Reynolds, J. D. 1966. Morphological Studies in Diapensiaceae. The embryology of Pyxidanthera Mich. Ph.D. thesis, University of South Carolina, Columbia, SC.

Rhoades, C., D. Loftis, J. Lewis, and S. Clark. 2009. The influence of silvicultural treatments and site conditions on American chestnut (Castanea dentata) seedling establishment in eastern Kentucky, USA. For. Ecol. Manag. 258: 12111218 .

Schafale, M. P. and A. S. Weakley. 1990. Classification of the natural communities of North Carolina: Third approximation. North Carolina Natural Heritage Program, Raleigh, NC. 321 p.

Schemske, D. W., B. C. Husband, M. H. Ruckelshaus, C. Goodwillie, I. M. Parker, And J. G. Bishop. 1994. Evaluating approaches to the conservation of rare and endangered plants. Ecol. 75: 584-606.

Schütz, W. 1997. Are germination strategies important for the ability of cespitose wetland sedges (Carex) to grow in forests? Can. J. Bot. 75: 1692-1699.

Schwartz, M. W. and S. M. Hermann. 1999. Is slow growth of the endangered Torreya taxifolia (Arn.) normal? Bull. Torrey Bot. Club 126: 307-312.

Shapiro, A., J. Zeimpfer, AND M. Bates. 2000. Reproductive ecology of the Sandhills pyxie moss. United States Army Environmental Research and Development Center, Champaign, IL. $26 \mathrm{p}$.

Sorrie, B. A., J. B. Gray, and P. J. Crutchfield. 2006. The vascular flora of the longleaf pine ecosystem of Fort Bragg and Weymouth Woods, North Carolina. Castanea 71: 129-161.

Thanos, C. A., K. Georghiou, and F. Skarou. 1989. Glaucium flavum seed germination-an ecophysiological approach. Ann. Bot. 63: 121130.

Thompson, P. A. 1970. Germination of species of Caryophyllaceae in relation to their geographical distribution in Europe. Ann. Bot. 34: 427-449.

Wang, G. G., W. L. Bauerle, and B. T. Mudder. 2006. Effects of light acclimation on the photosynthesis, growth, and biomass allocation in American chestnut (Castanea dentata) seedlings. For. Ecol. Manag. 226: 173-180.

Weakley, A. S. 2008. Flora of the Carolinas, Virginia, Georgia, northern Florida, and surrounding areas (Working Draft of 7 April 2008). $924 \mathrm{p}$.

Wells, B. W. 1929. A new pixie from North Carolina. J. Elisha Mitchell Sci. Soc. 44: 238-239.

Wells, B. W. And I. V. ShunK. 1931. The vegetation and habitat factors of the coarser sands of the North Carolina coastal plain: An ecological study. Ecol. Monogr. 1: 465-520. 